midores serão beneficiados com maior disponibilidade de produtos de melhor qualidade. Portanto, a nova embalagem pode ser recomendada com segurança para o mercado.

\section{LITERATURA CITADA}

ABRACEN. Retorno da caixas do tipo " $K$ ” aos produtores através das centrais de abastecimento. Curitiba, ABRACEN. 16/10/2000.(Informações enviadas via correio eletrônico: abracen@pr.gov.br).

CONTADOR, C.R. Avaliação social de projetos. São Paulo: Atlas, 1988. 316 p.
EMATER (Brasília-DF). Custo de produção/ha, 1998. Brasília,1998. n.p.

FNP Consultoria \& Comércio ( São Paulo, SP.). Agrianual: anuário da agricultura brasileira. São Paulo, 1999. 521 p.

HIRSCHFELD, H. Engenharia econômica e análise de custos. São Paulo: Atlas, 1998. 408 p. KARMEL, P.H.; POLASEK, M. Estatística geral e aplicada à economia. São Paulo: Atlas, 1976. 601 p. LUENGO, R.F. Desenvolvimento e análise econômica de embalagem para transporte $e$ comercialização de tomate e pimentão. Brasília: Embrapa-CNPH, 1999 (Relatório de Pesquisa). SÃO PAULO. SECRETARIA DA AGRICULTURA E ABASTECIMENTO. Projeto de avaliação de perdas pós colheita de produtos hortigranjeiros no Estado de São Paulo. São Paulo,1995. 74 p. (Pesquisa de campo).
TOPEL, R.M.M. Estudos de embalagens para produtos hortícolas: o caso da caixas do tipo " $K$ ". São Paulo: IEA, 1981. 29 p. (Relatório de pesquisa 17/81).

UENO, L.H. Perdas na comercialização de produtos hortifrutícolas na cidade de São Paulo. Informações Econômicas, São Paulo, v. 6, p. 6-7, 1976.

UENO, L.H.; TSUNECHIRO, A.; MAZZEI, A.R.; OKAWA, K. Relações entre os preços de produtos olerícolas no Estado de São Paulo. Agricultura em São Paulo, São Paulo, v. 36, 1989. p. 201-208.

WOILER, S.; MATHIAS, W.F. Projetos, planejamento, elaboração e análise. São Paulo:

Atlas, 1988. 294 p.

CAÑIZARES, K.A.; COSTA, P.C.; GOTO, R.; VIEIRA, A.R.M. Desenvolvimento de mudas de pepino em diferentes substratos com e sem uso de solução nutritiva. Horticultura Brasileira, Brasília, v. 20, n. 2, p.227-229, junho 2.002.

\title{
Desenvolvimento de mudas de pepino em diferentes substratos com e sem uso de solução nutritiva
}

\author{
Kathia A. L. Cañizares; Paulo César Costa; Rumy Goto; Ana R. M. Vieira \\ UNESP, Produção Vegetal/Horticultura, C. Postal 237, 18.603-970 Botucatu - SP. E-mail: kalcaniza@hotmail.com
}

\section{RESUMO}

O experimento foi conduzido na UNESP em Botucatu para determinar o melhor substrato e avaliar o efeito da solução nutritiva na produção de mudas de pepino. O delineamento experimental foi em blocos ao acaso em esquema fatorial, com quatro repetições. Os doze tratamentos foram constituídos de seis substratos e dois manejos diferentes: bandeja flutuando sobre água e bandeja flutuando sobre solução nutritiva. Os substratos foram: vermiculita, palha de arroz carbonizada; palha de arroz não carbonizada; $1 / 2$ palha de arroz carbonizada $+1 / 2$ palha não carbonizada; $1 / 2$ vermiculita $+1 / 2$ palha de arroz não carbonizada e um substrato a base de terra. As melhores mudas foram obtidas quando usado o susbtrato a base de terra flutuando sobre a solução nutritiva.

\begin{abstract}
Development of cucumber seedlings in different substrates with and without nutritive solution

The trial was carried out at the Universidade Estadual de São Paulo, in Botucatu (Brazil), to determine the best substrate and to evaluate the nutritive solution in cucumber seedlings production. The experimental design consisted of randomized complete block design, with four replications. The twelve treatments consisted of six substrates and two management forms (water floating and nutrition solution floating). The substrates were vermiculite, carbonized rice straw and not carbonized, carbonized rice straw + not carbonized rice straw, vermicullite + rice straw without carbonized and substrate prepared with soil mixture. The best treatment was substrate with soil mixture in nutritive solution.
\end{abstract}

(Aceito para publicação em 17 de dezembro de 2.001)

$\mathrm{A}$ lguns produtores de hortaliças no Brasil, cultivam intensamente pepino em ambientes protegido desde a década de 80 (Cañizares et al., 1996). O sucesso de uma produção começa pela obtenção de mudas de qualidade. Uma muda mal formada dará origem a uma planta com produção abaixo de seu potencial genético.

No Brasil, a introdução do sistema de produção de mudas em bandeja aliada a outras técnicas fez com que esta produção começasse a se modernizar, aumentando o volume de recursos financeiros gerados pelo setor (Minami,
1995). A obtenção de mudas em bandejas traz vantagens como ótima germinação, manejo facilitado, uniformidade das mudas, economia de água, menor dano às raízes no momento do transplante (Taveira, 1994; Minami, 1995; Tessarioli Neto, 1995).

Para a produção de mudas de pepino é aconselhável o uso bandejas de 128 células. Barros (1997) estudou o comportamento de pepino utilizando bandejas com 200 e 128 células, com volumes celulares de 16,36 e $72 \mathrm{~cm}^{3}$. O autor concluiu que os maiores valores para massa fresca e seca da parte aérea, raízes, total da planta e área foliar foram atingidos com os maiores volumes celulares das bandejas. A obtenção de mudas de pepino normalmente é feita em diferentes tipos de substratos, compostos de materiais orgânicos leves, corrigidos e enriquecidos de nutrientes solúveis, oferecendo à muda condições físicas adequadas de arejamento e retenção de água (Minami, 1995).

Na irrigação das mudas é comum o uso de água corrente, sendo escassos ou inexistentes estudos com solução nutritiva nessa fase de desenvolvimento, para as condições brasileiras. 
Tabela 1. Porcentagem de sobrevivência, altura da planta, área foliar e comprimento da raiz aos 27 dias após semeadura de mudas de pepino cultivadas em diferentes substratos, em água e em solução nutritiva. Botucatu, UNESP, 1999.

\begin{tabular}{|c|c|c|c|c|c|c|c|c|c|c|c|c|c|c|c|c|}
\hline \multirow{3}{*}{$\begin{array}{l}\text { Trata- } \\
\text { mento }\end{array}$} & \multicolumn{4}{|c|}{ Sobrevivência (\%) } & \multicolumn{4}{|c|}{ Altura $(\mathrm{cm})$} & \multicolumn{4}{|c|}{ Área-Foliar (dm²) } & \multicolumn{4}{|c|}{$\begin{array}{c}\text { Comprimento Raiz } \\
\text { (cm) }\end{array}$} \\
\hline & \multicolumn{2}{|c|}{ ÁGUA } & \multicolumn{2}{|c|}{ SOL } & \multicolumn{2}{|c|}{ ÁGUA } & \multicolumn{2}{|c|}{ SOL } & \multicolumn{2}{|c|}{ ÁGUA } & \multicolumn{2}{|c|}{ SOL } & \multicolumn{2}{|c|}{ ÁGUA } & \multicolumn{2}{|c|}{ SOL } \\
\hline & 94,5 & $\mathrm{Aa}$ & 90,5 & $\mathrm{Aa}$ & 4,2 & $\mathrm{Ba}$ & 6,8 & $\mathrm{Aa}$ & 0,19 & $\mathrm{Ba}$ & 0,46 & $\mathrm{Aa}$ & 20,2 & $A b$ & 23,3 & $A b$ \\
\hline PC & 51,2 & $A b c$ & 43,8 & $A b c$ & 2,7 & $\mathrm{Bbc}$ & 5,5 & $A b c$ & 0,16 & $\mathrm{Bbc}$ & 0,25 & $A b$ & 19,2 & $\mathrm{Bb}$ & 23,1 & $A b$ \\
\hline $\mathrm{N}$ & 40,5 & $A c$ & 42,0 & Ac & 2,2 & Bcd & 4,1 & Acd & 0,14 & Acd & 0,13 & $\mathrm{Ae}$ & 15,3 & $A b$ & 16,8 & $A c$ \\
\hline PCPN & 51,3 & $\mathrm{Ab}$ & 55,5 & $\mathrm{Ab}$ & 2,1 & $\mathrm{Bd}$ & 3,6 & Ad & 0,12 & $\mathrm{Bd}$ & 0,17 & Ad & 19,2 & $A b$ & 17,9 & $A c$ \\
\hline VE & 91,5 & $\mathrm{Aa}$ & 89,5 & $\mathrm{Aa}$ & 3,0 & $\mathrm{Bb}$ & 5,5 & $\mathrm{Ab}$ & 0,19 & $\mathrm{Ba}$ & 0,24 & $A b$ & 17,0 & $\mathrm{Bb}$ & 27,0 & $A a b$ \\
\hline VEPN & 85,5 & $\mathrm{Aa}$ & 83,8 & $\mathrm{Aa}$ & 2,6 & Bbcd & 5,0 & Abcd & 0,18 & Bab & 0,21 & $A c$ & 27,0 & $\mathrm{Ba}$ & 31,2 & $\mathrm{Aa}$ \\
\hline CV (\%) & & & 0,3 & & & & 8,0 & & & &, 4 & & & & 1,0 & \\
\hline
\end{tabular}

Substratos: SM: Substrato à base de terra da Fazenda São Manuel da UNESP, Botucatu; PC: palha de arroz carbonizada; PN: palha de arroz não carbonizada; PCPN: $1 / 2$ palha de arroz carbonizada + $1 / 2$ não carbonizada; VE: vermiculita; VEPN: $1 / 2$ vermiculita $+1 / 2$ palha de arroz não carbonizada. SOL: solução nutritiva.

Médias seguidas pelas mesmas letras maiúsculas na linha e minúsculas nas colunas, não diferem entre si pelo teste de Tukey, ao nível de 5 \% de significância.

O objetivo do presente trabalho foi determinar o melhor substrato e avaliar o uso de solução nutritiva na obtenção de mudas de pepino.

\section{MATERIAL E MÉTODOS}

O experimento foi conduzido em abril de 1999, em casa de vegetação de vidro climatizada, na UNESP em Botucatu. A temperatura no interior da estufa foi mantida em torno de $25^{\circ} \mathrm{C}$ e acima de $60 \%$ de umidade relativa do ar. $\mathrm{O}$ controle da temperatura foi feito com um termostato eletrônico que monitorava painéis evapotranspirativos CELDEX confeccionados com placas de celulose MUNTENS, circulação de ar forçada por exaustores e aquecedores de óleo.

O delineamento experimental foi em blocos ao acaso em esquema fatorial 6 x 2 , com 4 repetições, 16 mudas/bandeja, 3 bandejas/parcela.

Os 12 tratamentos foram resultantes de 6 substratos [vermiculita (VE); palha de arroz carbonizada (PC); palha de arroz não carbonizada (PN); $1 / 2$ palha de arroz carbonizada $+1 / 2$ palha não carbonizada (PCPN); $1 / 2$ vermiculita $+1 / 2$ palha de arroz não carbonizada (VEPN) e substrato a base de terra (SM)] e duas formas de manejo (imersão permanente em água ou em solução nutritiva). Os substratos foram compostos da seguinte proporção: $40 \mathrm{~L}$ de terra de barranco $+40 \mathrm{~L}$ de esterco curtido de gado +20 $\mathrm{L}$ de palha de arroz carbonizada +150 g de 4-14-8 + $50 \mathrm{~g}$ de super fosfato simples (Ballarin, 1996).

Sementes de pepino japonês híbrido Hokuho foram semeadas em bandejas de poliestireno expandido de 128 células (1 semente/célula) contendo os substratos. As bandejas permaneceram os primeiros 10 dias (desde a semeadura) sobre uma lâmina de água. Logo após, os tratamentos que receberam solução nutritiva, permaneceram por mais 17 dias numa lâmina de solução nutritiva, enquanto os demais permaneceram numa lâmina d'água sem nutrientes.

A solução nutritiva foi colocada por uma única vez. Esta foi composta de $\mathrm{N}=80, \mathrm{P}=45, \mathrm{~K}=60, \mathrm{Ca}=200, \mathrm{Mg}=48$, $\mathrm{S}=70, \mathrm{Cu}=0,05, \mathrm{Mn}=0,5, \mathrm{~B}=0,5$, $\mathrm{Zn}=0,05, \mathrm{Mo}=0,02$ e $\mathrm{Fe}=2 \mathrm{mg} . \mathrm{L}^{-1}$, baseado no balanço proposto por Sarruge (1975). A condutividade elétrica da solução esteve entre $2 \mathrm{e} 3{\mathrm{mS} . \mathrm{cm}^{-1}}^{-} \mathrm{o} \mathrm{pH}$ entre 5,5 e 6,5. Tanto a solução nutritiva quanto a água foram acondicionadas em pequenas piscinas, formando lâminas de $10 \mathrm{~cm}$, caracterizando assim um sistema hidropônico fechado, no qual o meio líquido não era movimentado.

Aos 27 dias após a semeadura avaliou-se a porcentagem de sobrevivência, altura da muda, área foliar e comprimento da raiz.

\section{RESULTADOS E DISCUSSÃO}

A solução nutritiva não teve influência na porcentagem de sobrevivência das mudas, porém, o tipo de substrato utilizado teve efeito significativo (Tabela 1). As mudas cultivadas no substrato SM, na VE ou no tratamento com VEPN apresentaram maior sobrevivência, independente do fornecimento de solução nutritiva.

O desenvolvimento das mudas foi afetado pelos substratos e pelo fornecimento de solução nutritiva. As mudas cultivadas no substrato SM atingiram maior altura $(6,8 \mathrm{~cm}) \mathrm{e}$ área foliar $(0,46$ $\mathrm{dm}^{2}$ ) quando colocadas em solução nutritiva (Tabela 1).

A PN teve efeito negativo sobre as plantas, seja em forma isolada ou junto à PC, flutuando em água ou em solução nutritiva, prejudicando a altura, área foliar e comprimento de raiz. Porém, os efeitos negativos foram amenizados quando as mudas foram mantidas sobre a solução nutritiva. Por exemplo, de $2,1 \mathrm{~cm}$ de altura das mudas crescidas em PCPN, sobre água, conseguiram atingir $3,6 \mathrm{~cm}$ de altura sobre a solução nutritiva.

$\mathrm{O}$ aumento do comprimento da raiz foi estimulado pela solução nutritiva nas mudas cultivadas em PC, VE e VE + $\mathrm{PN}$, sendo que as mudas cultivadas neste último substrato atingiram maior comprimento de raiz (Tabela 1).

Os resultados obtidos no presente experimento ficam justificados plenamente pelo fato de que, dos substratos utilizados, aquele à base SM aporta com grande quantidade de nutrientes além de fornecer condições ideais de retenção de 
água, arejamento e drenagem. É muito provável também que o uso da PN tenha prejudicado o desenvolvimento das mudas devido à deficiência de nitrogênio em decorrência à alta relação carbono:nitrogênio que a palha crua apresenta.

Estes resultados estão de acordo com os critérios de Klougart (1982), que conclui que o uso de soluções nutritivas pouco concentradas permite a obtenção de mudas de alta qualidade quando o substrato utilizado fornece condições físicas e químicas ideais.

Nas condições desse experimento, na escolha da muda com vigor na parte aérea e raiz e com boa porcentagem de sobrevivência, recomenda-se o substrato à base de terra ou também o substrato vermiculita e o uso de solução nutritiva para a produção de mudas de pepino japonês de alta qualidade.

\section{LITERATURA CITADA}

BALLARIN, J.T. Relatório final da residencia. Botucatu: UNESP-FCA, 1996, 40 p. (Relatório). BARROS, S.B.M. Avaliação de diferentes recipientes na produção de mudas de tomate (Lycopersicum esculentum Mill) e pepino (Cucumis sativus L.) Piracicaba, 1997. 70 p. (Dissertação Mestrado). ESALQ.

CAÑIZARES, K.A L.; IOZI, R.N; STRIPARI, P.C.; GOTO, R. Enxertado, japonês fica mais brilhante. Agrianual 97. Anuário Estatístico da Agricultura Brasileira. FNP, Consultoria \& Comércio, 1996. p. 332-33.
KLOUGART, A. Substrates and nutrient flow. Acta Horticulturae, v. 150, p. 296-313, 1982.

MINAMI, K. Produção de mudas de alta qualidade em horticultura. Campinas: Fundação Farah Maluf, 1995. 128 p.

SARRUGE, J.R. Soluções nutritivas. Summa Phytopatologica, v. 1, p. 231-3, 1975.

TAVEIRA. J.A.M. Produção de mudas em containers. 1994.9 p. (mimeografado).

TESSARIOLI NETO, J. Recipientes, embalagens e acondicionamento de mudas de hortaliças. In: MINAMI, K.; GONÇALVES, A.L.; PENTEADO, S.R.; SCARPARE FILHO, J.A.; SILVEIRA, R.B.A. Produção de mudas de alta qualidade em horticultura. São Paulo: Fundação Salim Farah Maluf, 1995. p. 59-64.

YURI, J.E.; SOUZA, R.J.; FREITAS, S.A.C. RODRIGUES JÚNIOR, J.C.; MOTA, J.H. Comportamento de cultivares de alface tipo americana em Boa Esperança. Horticultura Brasileira, Brasília, v. 20, n. 2, p. 229-232, junho, 2.002.

\title{
Comportamento de cultivares de alface tipo americana em Boa Esperança ${ }^{1}$
}

\author{
Jony E. Yuri ${ }^{2}$, Rovilson J. de Souza ${ }^{2}$; Silvio A.C. de Freitas ${ }^{3}$; Juarez C. Rodrigues Júnior ${ }^{3}$; \\ José Hortêncio Mota ${ }^{2}$ \\ ${ }^{2}$ UFLA, C. Postal 37, 37.200-000 Lavras - MG. ${ }^{3}$ REFRICON, Rod. Regis Bittencourt s/n km 294, 06.850-000 Itapecerica da Serra-SP; \\ E.mail: jony@ufla.br
}

\section{RESUMO}

Os experimentos foram conduzidos em estufas (túnel alto) no município de Boa Esperança (MG), para avaliar cultivares de alface do grupo americana ("Crisphead lettuce”), em duas épocas de plantio (outubro e março). As cultivares (Cassino; Legacy; Lucy Brown; Lorca; Lady e Raider) foram plantadas em delineamento de blocos casualizados com quatro repetições. Para a primeira época (outubro), a produção comercial variou de 29,3 t.ha ${ }^{-1}$ a 37,6 tha ${ }^{-1}$ e circunferência da cabeça de 40,07 a 42,95 cm, não apresentando diferenças significativas entre cultivares. Na segunda época de plantio (março), sobressaíram-se as cultivares Raider, Cassino, Lady, Legacy e Lorca com produção comercial de 42,6; 41,6; 39,3; 37,3 e 32,5 t.ha ${ }^{-1}$, respectivamente. Quanto à circunferência de cabeça comercial, as cultivares Lady, Raider, Lucy Brown e Cassino, foram superiores às demais cultivares, com 48,15; 46,69; 45,90 e 45,67 cm respectivamente, sem diferirem significativamente entre si.

Palavras-chaves: Lactuca sativa L., cultivo protegido, competição.

\begin{abstract}
Performance of crisphead lettuce cultivars in Boa Esperança, Brazil

The experiment was carried out at green house, in Boa Esperança, Brazil, to evaluate lettuce cultivars (Cassino; Legacy; Lucy Brown; Lorca; Lady and Raider), crisphead group, in two planting seasons (October and March). The experimental design was of randomized blocks with four replications. For the first season (October), the commercial yield, varied from 29.3 t.ha $^{-1}$ to 37.6 t.ha $^{-1}$ and head circumference from 40.07 to $42.95 \mathrm{~cm}$, without significant difference among cultivars. At the second planting season (March), cvs. Raider, Cassino, Lady, Legacy and Lorca presented a commercial yield of 42.6; 41.6; 39.3; 37.3 and 32.5 t.ha ${ }^{-1}$. Cvs. Lady, Raider Lucy Brown and Cassino, were superior to the other cultivars, without significant differences among themselves, with $48.15 ; 46.69 ; 45.90$; and 45.67 $\mathrm{cm}$ respectively.
\end{abstract}

Keywords: Lactuca sativa L., protect cultivation, competition.

\section{(Aceito para publicação em 17 de dezembro de 2.001)}

$\mathrm{N}$ o Brasil, a alface é a hortaliça folhosa de maior aceitação pelo consumidor. Apresentando elevados teores de vitaminas e de sais minerais, indispensáveis na dieta alimentar, além de possuir baixo teor de calorias, aconselhável nas dietas por ser de fácil diges- tão. Atualmente a produção nacional é de 260.000 toneladas por ano; a região Sudeste é responsável por $70 \%$ dessa produção (IBGE, 1996a, 1996b).

O desenvolvimento da alface é bastante influenciada pelas condições ambientais. Temperaturas acima de $20^{\circ} \mathrm{C}$ estimulam o seu pendoamento, que é acelerado à medida que a temperatura aumenta. Dias longos associados a temperaturas elevadas, aceleram ainda mais o pendoamento, mas há variação de comportamento entre cultivares (Viggiano, 1990). O melhor desenvol-

\footnotetext{
${ }^{1}$ Parte do trabalho para elaboração da dissertação de mestrado em Agronomia, área de concentração em Fitotecnia pela UFLA, MG.
} 